\title{
LAS ASOCIACIONES DE CONSUMIDORES Y SU FUTURO. REPRESENTACION
}

\author{
POR \\ FEDERICO ROMERO HERNÁNDEZ \\ Secretario General del Excmo. Ayuntamiento de Málaga \\ Profesor Titular de Derecho Administrativo
}

\begin{abstract}
SUMARIO: I. LA ASOCIACIÓN: 1. Asociación y representación ciudadana "uti socius vel uti cives». 2. Pluralidad de supuestos asociativos y su concepción estricta. 3. La asociación de consumidores y usuarios: Significado y efectos del artículo 51.2 de la Constitución española: su comparación con el derecho de asociación protegido por el artículo 22. 4. Aspectos del mandato constitucional de promoción de las asociaciones de consumidores. La virtualidad derivada del diverso significado de las normas constitucionales. 5 . Conceptos y naturaleza de las asociaciones de consumidores y usuarios. Referencia al procedimiento de constitución.-II. LA REPRESENTACIÓN: 1. Advertencia preliminar. 2. Acepciones de la representación: a) La representación como delegación, sustitución o vicariato. b) La representación escénica y su aplicación conceptual: b. 1 La necesidad de un escenario social apropiado. b.2 La necesidad de un argumento expreso y sus manifestaciones: Información. Afectación. Confianza. 3. Representación jurídica, política y social. 4. Aspectos de la representatividad de consumidores y usuarios: a) Presencia. b) Intensidad. c) Organización (viabilidad económica y financiera). d) La configuración positiva del derecho de representación. III. ÁMBITOS DE REPRESENTACIÓN: 1. En el ámbito estatal. $2 . \quad$ En el ámbito autonómico. 3. En el ámbito provincial. 4. En el ámbito municipal.-IV. RÉGIMEN JURIDICO.-V. CONCLUSIONES.
\end{abstract}

\section{LA ASOCIACION}

\section{La asociación y representación ciudadana uti socius vel uti cives}

Una de las manifestaciones de las democracias debidamente consolidadas, es la vitalidad del ciudadano, que no sólo se enfrenta a la Administración en el ámbito de un procedimiento o un proceso, donde se ponen en juego sus derechos subjetivos o intereses personales, sino que se responsabiliza de un aparte de los intereses colectivos, de la ures publica». También define esa consolidación, que dicha participación no se encauza sólo a través de los partidos políticos, o en tiempo de elecciones, sino que el dinamismo social propicia diversas formas de asociación que representan intereses sectoriales o específicos de los ciudadanos, cuya relevancia política es sólo indirecta. Esta idea, que se ha expuesto de muy diversas formas, lo fue de manera temprana por ALEXIS DE TOCQUEVILLE, diciendo que «el país más democrático de la Tierra es

REVISTA DE ÉSTUDIOS.-3 
aquél en el que los hombres más han perfeccionado el arte de perseguir conjuntamente el objeto de sus comunes deseos y han aplicado al mayor número de objetos esa nueva ciencia» (1).

Pero no siempre el Estado, y quien encarna en su diversos momentos el poder político que dirige su ejecutivo, ve este dinamismo con entera complacencia. Toda forma de pluralismo social fuerte conlleva una mayor dificultad para gobernar, si bien es evidente que puede contribuir a mejorar la sensibilidad del gobernante.

Recordando de nuevo a TOCOUEVILLE, resulta lúcida también una de sus afirmaciones: "Constituye, pues, una ilusión creer-decíaque, aunque se reprima el espíritu de asociación en un punto, no dejará de desarrollarse con el mismo vigor en todos los demás, y que bastará con permitir a los hombres ejecutar en común ciertas empresas para que se apresuren a intentarlo» (2). Es decir, la limitación puntual de un tipo de asociaciones tiene siempre una repercusión negativa en el status positivus et activae civitatis de que hablara JELLINEK, y que constituye el soporte jurídico del Estado social y democrático de Derecho, resintiendo la salud y virtualidad del tejido social. Más aún, como tendremos ocasión de explicar casi en seguida, la pasividad de las Administraciones Públicas en la promoción de determinadas asociaciones, supone una forma de transgresión del ordenamiento jurídico, al no cumplir la función promocional que se concreta en un mandato positivo (art. 51.2 de la Constitución) y que se constituye además como principio general informador de ese mismo ordenamiento (art. 53.3 de la Constitución y 1.․1 de la ley de 19 de julio de 1984, número 26/1984, General para la Defensa de los Consumidores y Usuarios -desde ahora ley de Consumo).

\section{Pluralidad de supuestos asociativos y su concepción estricta}

FERNÁNDEZ FARRERES, que ha realizado un reciente estudio sobre las asociaciones desde la específica perspectiva del artículo 22 de la Constitución (3) -después de enumerar los diversos supuestos asociativos, que no son sólo reconducibles al artículo 22 de la Constitución, sino que tienen además una mención directa en otros preceptos constitucionales (a saber: partidos políticos, sindicatos de trabajadores y asociaciones empresariales, asociaciones profe-

(1) ALEXIS DE TOCQUEVILLE: La democracia americana. Alianza Editorial, vol. II. Edición Española, 1984, pp. 96.

(2) Obra y pp. citadas.

(3) Autor citado, Asociaciones y constitución. Ed. Civitas. Col. Monografías. En especial, pp. 148 y ss. 
sionales de jueces, magistrados y fiscales, comunidades y confesiones religiosas, $y$, en fin, las propias asociaciones de consumidores y usuarios, sin olvidar la posibilidad de otras asociaciones no específicamente previstas)-, deslinda el concepto estricto de la asociación, delimitándolo, por un lado, respecto de las llamadas Corporaciones de Derecho Público (creadas por la ley directamente o por resolución administrativa) y de las asociaciones civiles y mercantiles, por otro (en las que el ánimo de lucro constituye una clara finalidad diferenciadora). En efecto, según dicho autor, unión entre personas, lícito fin asociativo y estructura estable y permanente de la agrupación, constituyen, pues -junto con los elementos diferenciadores antes enunciados-, los requisitos determinantes de una asociación estricto sensu, en los que cabe incluir, desde luego, sin duda alguna, a las asociaciones de consumidores y usuarios.

\section{La asociación de consumidores y usuarios: Significado y efectos del artículo 51.2 de la Constitución española: su comparación con el derecho de asociación protegido por el artículo 22}

Según acabamos de ver, las asociaciones de consumidores y usuarios están específicamente contempladas en la Constitución española. Su artículo 51, utilizando la doble técnica garantizadora y promocional de nuestra Constitución, manda a los poderes públicos prestar dicha garantía para la defensa de consumidores $y$ usuarios, protegiendo, mediante procedimientos eficaces, la seguridad, la salud y los legítimos intereses económicos de los mismos.

Este primer párrafo, que plantea una acción directa de los poderes públicos, difiere del segundo, en el que el poder público realiza una actuación fomentadora del protagonismo del consumidor y usuario a través de sus organizaciones. Ha de llamarse la atención, sin embargo, sobre el hecho de que el indicado párrafo termina remitiéndose a los términos que la ley establezca, sin que dicha remisión esté recogida, como es obvio, en la antes indicada función garantizadora. Por otra parte, el artículo 22.1 de la Constitución española, al reconocer el derecho de asociación, tiene, como ha puesto de manifiesto FERNÁNDEZ FARRERES (4), dos aspectos: uno positivo y otro negativo, de los cuales el primero, a partir y de la conexión entre este derecho fundamental y sus posibles límites, dentro del marco global de la Constitución y del Estado de Derecho en el que se sitúa, comporta que el mismo no puede quedar condicionado o dependiente de las restricciones que

(4) Obra citada, en especial pp. 43 y ss. 
en su caso pretendieran establecer las leyes, sino que es en la propia superley donde pueden localizarse las posibles y únicas limitaciones que excepcionen y rompan la regla general del libre ejercicio del derecho. Como dice dicho autor, ello supone que la ley de Asociaciones de 24 de diciembre de 1964 se ha visto derogada específicamente en este aspecto, en cuanto al propósito de la licitud y determinación de fines previstos en la misma. Estamos de acuerdo en que una cosa son «los requisitos o exigencias propias para que el Estado reconozca personalidad jurídica a las asociaciones que así lo pretendan, y otra cosa es que en realidad pasen a operar como condición o presupuesto de la lícita exigencia de la asociación». Conduce todo ello al problema de si es jurídicamente admisible la categoría de "asociaciones no personas jurídicas», o, por contra, según nuestro ordenamiento, no hay otras asociaciones que las personificadas. La conclusión no puede ser otra que la validez del pacto asociativo lícito -pues así está garantizado por nuestra Norma fundamental- sin perjuicio de que el Estado sea quien declare qué asociaciones son personas jurídicas por reunir los aludidos requisitos o exigencias. Es decir, se produce una verdadefra gradación que va desde la simple asociación sin personalidad, pero válidamente constituida y capaz de producir a través de sus miembros, a título individual, los efectos jurídicos que previamente se hayan convenido en virtud del pacto, las asociaciones con personalidad jurídica, que requieren de este añadido formal cuando su estructura organizativa y volumen patrimonial asi lo necesitan, $y$, finalmente, aquellas que obtienen la declaración de utilidad pública, conforme a las previsiones del artículo $4 .^{\circ}$ de la ley de Asociaciones 191/1964, por así cumplir los fines previstos en el mencionado precepto.

\section{Aspectos del mandato constitucional de promoción de las asociaciones de consumidores. La virtualidad derivada del diverso significado de las normas constitucionales}

Como conclusión de lo antes expuesto, existe una plena capacidad asociativa sin restriciones de los consumidores y usuarios que por su propia finalidad y medios coherentes no deben tener problemas con respecto al ilícito penal, que es el único límite previsto por la Constitución, aunque con un deber de inscripción en el Registro específico a los solos efectos de publicidad, la garantía de una defensa directa de los consumidores y usuarios por parte del poder público y un deber de promoción de la información y educación de los consumidores y usuarios y de sus asociaciones que ya no dependen de un ulterior desarrollo legislativo en cuanto 
que las Leyes estatales y autonómicas ya promulgadas pueden servir de suficiente marco legislativo para conseguir los indicados objetivos constitucionales. Como veremos más adelante, la Ley 26/1984, de 19 de julio, general para la Defensa de los Consumidores y Usuarios, para todo el ámbito del Estado, y la Ley 5/1985, de 8 de julio, para consumidores y usuarios de Andalucía, son instrumentos jurídicos iniciales capaces de generar una organización suficiente y eficaz en todo el país y en Andalucía. Se patentiza aquí una vez más algo que se expuso con oportunidad por Alejandro Nieto (5), en cuanto al distinto nivel de vinculación constitucional que las normas de nuestra Ley Fundamental tienen. En efecto, cabe preguntarse si la simple promulgación de las Leyes que en los ámbitos estatal y autonómico acabamos de citar deben servir sólo para tranquilizar el cumplimiento del artículo 51.2 de la Constitución, o la fuerza normativa del mismo obliga a que la letra de esas Leyes no sea muerta, exigiendo una actividad material de la Administración que, desde luego, debe estar acompañada por la de los propios consumidores y usuarios, en cuanto al efectivo desarrollo de dicho artículo. Por supuesto, es esta última la interpretación que más se adecua al ordenamiento jurídico, por lo que la creación y el funcionamiento de los órganos previstos en las Leyes indicadas y el uso del derecho de representación, consulta y participación de las asociaciones de consumidores y usuarios constituyen un verdadero derecho público subjetivo exigible ante la jurisdicción contenciosa en los términos del artículo 106.1 de la Constitución y los específicos preceptos de la Ley Jurisdiccional Contenciosa de 27 de diciembre de 1956.

\section{Concepto y naturaleza de las asociaciones de consumido- res y usuarios. Referencia al procedimiento de constitu- ción}

Durante algún tiempo, una línea jurisprudencial, relativamente estable, mantenía la adquisición de la personalidad jurídica en virtud del simple pacto asociativo, ya que la inscripción en un registro público lo era sólo a los efectos de publicidad. Se daba así una interpretación al artículo 22.3 de la Constitución española que quizá trascendía de la intención del legislador constitucional (así Sentencias del Tribunal Supremo de 3 de julio y de 7 de diciembre de 1979 , de 3 de julio de 1980, de 4 de noviembre de 1981, de 6 de octubre de 1984, etc.). Incluso durante el período a que se refieren las Sentencias que acabamos de recoger, la propia jurisprudencia

(5) «Peculiaridad juridica de la norma constitucional», en RAP núms. 100-102, vol. I, enero 1983, p. 371. 
tenía dudas y vacilaciones con respecto a la hermenéutica que se acaba de señalar, y así hay Sentencias como la de 27 de octubre de 1981, que indicaba que el pleno ejercicio del derecho asociativo requería la inscripción registral. Como anticipamos antes, según FERNÁNDEZ FARRERES (6), la indecisión jurisprudencial que acabamos de acusar derivaba muchas veces de la confusión ente el libre ejercicio del derecho asociativo con la adquisición, además, de una personalidad jurídica. Esta dificultosa situación estaba propiciada por la Ley de Asociaciones de 1964, de la que eran lógicamente deducibles las dudas dogmáticas de si la existencia de la asociación coincide con el nacimiento y constitución de la organización o, por contra, se requiere de un acto administrativo de constatación y comprobación que, muchas veces, se realizaba mediante la inscripción en un registro.

Aunque, en realidad, a la Ley de Asociaciones le importaba mucho menos el tema jurídico de la personificación, porque sobre todo atendía al aspecto político del control de las asociaciones que nacían, la verdad es que la Ley ha contribuido a una comprensión, aunque sea para reaccionar en sentido contrario, para evitar que el registro se convirtiese en un mero escaparate de las asociaciones constituidas -como dice SANTA MARÍA PASTOR-, entendiendo que todas las no inscritas eran sociedades secretas. Como advierte CAPILLA RONCERO, personificación jurídica y publicidad constituyen dos conceptos, si no identificables, estrechamente unidos, pues el ingrediente de la trascendencia, en cuanto al primero de ellos, resulta imprescindible.

Podemos asi concluir, en términos generales, que sólo aquellas asociaciones que acceden a un registro alcanzan la personalidad jurídica, pero que la función de éste no es la de servir como medio de control preventivo, sino como instrumento de una función reglada de constatación, cuyo control en un Estado democrático compete, en su caso, al Poder Judicial.

Refiriéndonos específicamente a las asociaciones de consumidores $y$ usuarios, podemos considerarlas como agrupaciones representativas de este sector ciudadano y que, constituidas con arreglo a la Ley de Asociaciones y a la legislación cooperativa, tienen como finalidad la defensa de los intereses de ese grupo ciudadano, incluyendo su información y educación, bien sea con carácter general, bien en relación con productos o servicios determinados. Estos intereses protegidos que, según el mandato constitucional, no se refieren sólo a la salud y a la seguridad, sino

(6) FERNÁNDEZ farRERES, ob. citada: 
también a los de naturaleza económica y social. Tales asociaciones alcanzan en este caso la personalidad jurídica y la plenitud de los beneficios previstos por la ley una vez que obtienen la inscripción en el Registro en el Ministerio de Sanidad y Consumo, aunque han de reunir las condiciones y requisitos que reglamentariamente se establezcan para cada tipo de beneficio. Esta conceptuación de la asociación es claramente deducible del artículo 20 de la Ley estatal de Consumo, y, desde luego, comporta la sustitución del registro a que alude la Ley de Asociaciones, por la que se residencia en el Ministerio de Sanidad y Consumo, que acabamos de citar, que dota de la publicidad necesaria a la asociación o cooperativa y que sirve para cumplir la función administrativa de constatación para la personalidad jurídica, ampliándolo a esta última clase de asociaciones.

Además de esta delimitación positiva, cabe una de carácter negativo, que el artículo 21 de la Ley de Consumo dicha conecta con el ánimo directo o indirecto de lucro, bien por incluir a sociedades mercantiles, bien por cualquier forma de actuación que comporte una desviación de los fines de interés público de los consumidores y usuarios, a que deben orientar su actuación, como puede ser la percepción de ayudas o subvenciones a empresas suministradoras de bienes, productos o servicios, o por realizar publicidad comercial.

\section{LA REPRESENTACION}

\section{Advertencia preliminar}

Una vez delimitado el concepto de asociación, nos toca ahora analizar su vertiente representativa. Cuando aquí se habla de representación (y ambos aspectos los vamos a desarrollar), tanto cabe referirlo a cuál es el papel que juegan las asociaciones en sí, como órganos apoderados por el conjunto de los ciudadanos en cuanto consumidores y usuarios, como el agrado de presencia y participación de dichos órganos e instituciones en el conjunto social y en la estructura política del Estado.

\section{Acepciones de la representación}

a) La representación como delegación, sustitución o vicariato.

La representación es un concepto complejo, con muy diversas acepciones, que en lo único que coinciden es, si lo referimos al campo de lo social, político o jurídico, y no a lo psicológico, en la 
actuación de una persona, o una minoría, en el lugar de otra persona o personas, o una mayoría.

El actuar de una minoría uen representación» de otro grupo mayor se justifica, según algunas teorías, por virtud de una delegación previa más o menos explícita y que comporta una delimitación del alcance y contenido del apoderamiento. La sustitución o el vicariato apuntan no tanto a la justificación de la relación, sino al efecto mismo que produce y según determinadas teorías políticas (7), que consideran absurdo hablar del mandato y procuran sacar la representación política y social de los términos estrictamente jurídicos para trasladarlos a los de la legitimación o la eficacia. Estas conceptuaciones de la representación, en un sentido amplio, y que, desde luego, se matizan al conectarlas con diversas expresiones históricas que, sobre todo en el campo de lo político y social, se han producido, requieren una ulterior y más definida referencia. Sin embargo, nos interesa hacer unas previas consideraciones de índole sociológica que pueden, quizá, ilustrar posteriores determinaciones jurídicas.

\section{b) La representación escénica y su aplicación conceptual.}

Utilizando el sentido que la representación escénica puede aportar para una perspectiva distinta $-y$, si ustedes quieren, sorprendente- de la representación que se da en las asociaciones, según la doble consideración a que nos referimos al principio de este apartado -es decir, en relación con sus representados y frente a la sociedad y el Estado- nos parece conveniente recordar las apreciaciones hechas al respecto por un filósofo (8), en cuanto que las minorías (en este caso las personas asociadas) representan, encarnan o personifican el drama mayoritario de la sociedad. En el teatro clásico, la máscara incorpora el elemento técnico para aumentar la calidad acústica, y ello conduce después a la idea de la «per-sona», de la "per-sonificación». La máscara es la persona y viceversa.

b). 1 Pues bien, la posibilidad de representación, es decir, que una persona física o jurídica represente a un grupo, requiere un contexto adecuado que dote a esa personificación de todo su significado posible. La representación, como la "careta», sin un ambiente dramatizado, carece de sentido y es incapaz de explicar el alcance y significado de la mueca o la sonrisa, del atuendo, o sus complementos, cuya relatividad es absoluta respecto de la escenifi-

(7) Así, ESMEIN: Droit Constitucionel. París.

(8) JULIÁN MARÍAS: La estructura social. Col. Almón. Ediciones de la Revista de Occidente. Madrid, 1972, pp. 67 a 72. 
cación. Se requiere, pues, un escenario social, «un punto de encuentro y una visibilidad» (9), cuya magnitud y complejidad dependen del grado de desarrollo de la sociedad. En el "ágora» ateniense la democracia directa era posible; no así en el complejo que constituyen los Estados Unidos de América. Con todo ello quiero conducir a la idea de que resulta imprescindible un determinado grado de vida pública y una voluntad de preparar un espacio determinado para la plena virtualidad de la asociación, cuestión ésta que no sólo depende de las vigentes expresiones legales a este exclusivo respecto, sino que exigen una estructura organizativa del Estado en donde la asociación encaje con plena eficacia y significado. Magnitud del escenario, elementos que lo configuran, disposiciones para la audiencia, etc., son instrumentos cuyo valor metafórico no es simplemente literario, sino que tienen una concreta aplicación práctica a nuestro caso para demandar un espacio social que depende en gran parte del conjunto de normas de organización de las Administraciones Públicas.

b).2 La exigencia de un "argumento» constituye también un requisito necesario para la virtualidad de toda representación social. Este «argumento» o «asunto», en el sentido que ahora le damos, supone una trama de acontecimientos que caminan hacia un desenlace. Algunas veces, las disposiciones legales $-y$ así ocurre, por ejemplo, con las Leyes Estatales y Autonómicas del Consumo, que analizaremos- confunden lo que es función con lo que es fin u objetivo, pero, en todo caso, esquematizan (desde luego por razones jurídico-técnicas) algo que sólo el grupo social puede enriquecer con el conocimiento y vivencia del argumento que le toca interpretar. El "asunto» que deben llevar entre manos las asociaciones es algo mucho más rico y concreto que las expresiones normativas que lo definen, amparan o habilitan, y por ello resultan imprescindibles una serie de factores que vamos a tratar de sintetizar.

El primero de ellos es el derecho a la información. Resulta, sin duda, imprescindible el conocimiento del "asunto de que se trata». El artículo $2 .^{\circ}$ del apartado d) de la Ley estatal para la Defensa de los Consumidores y Usuarios de 19 de julio de 1984 (que hemos venido citando como Ley estatal del Consumo) configura ese derecho subjetivo e irrenunciable (ver párrafo $3 .^{\circ}$ del art. $2 .^{\circ}$ citado), en cuanto que la remisión del artículo 51 de la Constitución, en su párrafo $22^{\circ}$, "a los términos que la ley establezca», ha acaecido ya como consecuencia de la promulgación de la ley a que nos estamos refiriendo. No nos corresponde en este momento

(9) En frase de JULlán MARÍAS ob. cit., p. 67. 
desarrollar en profundidad el contenido de ese derecho, pero sí nos importa señalar la indudable relación del conocimiento del argumento social con la configuración legal del citado derecho, ya que se constituye en una verdadera premisa para la eficacia de la representación. Ha de enfatizarse también que toda información comporta formación y educación y que, a su vez, estas últimas presuponen aquélla. La educación y la formación se configuran tambien como un auténtico derecho regulado en el capítulo $6 .^{\circ}$ de la Ley autonómica del Consumo (Ley de Consumidores y Usuarios de Andalucía de 8 de julio de 1985, BOJA de 17 de julio), y en el capítulo $5 .^{\circ}$ de la Ley estatal del Consumo. Este derecho a la información es ejercitable no sólo frente a las Administraciones Públicas, sino frente a los particulares, con múltiples manifestaciones, como son la veracidad en la publicidad (arts. $8 .^{\circ}$ de la Ley General del Consumo y 12 de la Ley autonómica). En definitiva, esta formación e información comportan una dimensión proyectiva en la andadura del consumidor o usuario mediante un pleno conocimiento, un absoluto "saber estar», en una sociedad que se ha definido como «de consumo».

El segundo de los elementos o factores a considerar es el de la afectación misma, es decir, difícilmente un grupo social se puede sentir representado si no se hace notable la identificación de la actuación del representante con los problemas vitales, de cualquier tipo, correspondientes a las mayorías que son representadas.

Finalmente, se requiere una confianza en aquellos que ostentan la representación que ha de producirse, tanto en el acto de depósito del asunto en manos del representante, como en la esperanza de que lo gestionará adecuadamente. Dicho de otro modo, toda confianza supone una disponibilidad de apoyarse en los demás para realizar algo, es tener fe en que la actuación conjunta significa una mejora de la gestión por medio del representante, porque se espera que la ejecución de los asuntos que se han entregado va a ser más eficaz por medio de una visión global. La confianza, pues, se genera tanto en el acto de depósito del asunto como en la esperanza de su continua realización adecuada. Este elemento, que lo hemos enunciado enfatizando el componente psicológico, se traduce, desde el punto de vista jurídico, en una constante intercomunicación de los representantes con sus mandatarios.

\section{Representación política, jurídica y social}

Debemos consignar -aunque para algunos pueda considerarse obvio- que entre la representación jurídica y la política o social no sólo no existe una coincidencia de límites conceptuales, sino que se 
mueven en planos diferentes, aunque todos se fundamenten sobre el núcleo común de la sustitución personal de que hablamos. En la representación política y social existe un componente fiduciario que se manifiesta de modos diversos, según el sistema político, pero, en todo caso, requiere una importante dosis de libertad y de sentido comunitario. Sin perjuicio de que más adelante nos detengamos en ello, lo que sí nos importa ahora recalcar, antes de entrar en consideraciones estrictamente jurídicas, es que la representación política y social de los consumidores, a través de sus asociados, requiere una conciencia de su trascendencia en los citados planos, concretamente en actuaciones específicas que derivan de un genuino poder conferido para autogestionar los medios de satisfacción de verdaderas necesidades sociales.

Por lo que a la representación jurídica respecta, ha de recordarse cómo ésta se produce estrictamente no sólo cuando se es un mero transmisor de la voluntad del administrado, convertido así en simple vehículo o portavoz del mismo, o cuando la representación necesita de un segundo acto jurídico para imputar la voluntad del representante sobre el representado, tras la actuación de aquél, sino que sólo se da cuando el representante declara su voluntad, pero vale para el otro, para el representado, ya que fue precedido de un negocio de apoderamiento. Es elemental y conocida la clasificación de las formas de representación en: voluntaria (derivada del pacto de los sujetos intervinientes) y legal, que se establece por obra de la norma misma (la mayoría de las veces por razones de necesidad, como es la institución o tutela).

Pues bien, con independencia de la vertiente política y social, y con respecto a la representación de los consumidores a través de sus asociaciones, me parece importante detenerse en la posible interpretación del artículo $2 .^{\circ}$ de la Ley de Consumo estatal. Como es sabido, en dicho precepto se configuran los derechos de los consumidores y usuarios que deben ser protegidos en cumplimento del apartado $1 .^{\circ}$ del artículo 55 de la Constitución española. Debe hacerse notar que así como hay una enumeración de derechos que se predican directamente del consumidor o usuario, hay otros $-y$ ello queda mucho más claro en la redacción del artículo $4 .^{\circ} 4$ de la Ley de Consumo autonómica- que parece sólo pueden ser ejercitados a través de sus organizaciones y asociaciones propias. ¿Ello quiere decir que la protección de todos esos derechos sólo puede canalizarse por medio de las aludidas personas morales? Para contestar a esa pregunta deben ser tenidos en cuenta dos grupos de consideraciones: por un lado, que lo que se ha dado en llamar libertad negativa de asociación, que supone el reconocimiento de un ámbito de autonomía personal, que, desde luego, también se 
tiene como consumidor, y que constituye un aspecto importante de representación a los efectos de considerarla también desde este lado negativo, nos debe llevar a la conclusión de que la manifestación de los derechos enumerados del consumidor y usuario son derechos subjetivos y personales del mismo, como hemos venido reiterando, que no se interiorizan en la asociación, ni requieren de su intermediación. Así lo son, sin duda, los enumerados en los párrafos $1 .^{\circ}$ a $3 .^{\circ}$ y $5 .^{\circ}$ a $7 .^{\circ}$ de la Ley autonómica del Consumo.

La segunda de las consideraciones se refiere a que, precisamente aquellos derechos que el artículo $4 .^{\circ}$ del párrafo $4 .^{\circ}$ de la Ley autonómica del Consumo prevé como ejercidos a través de la organización o asociación [a saber: «a) La participación en las actividades de las Instituciones Públicas andaluzas que directamente les afecten; b) la audiencia en consulta, para la elaboración de las disposiciones de carácter general que pueden interesarles o afectarles, y en los términos legalmente establecidos; c) la representación de los derechos e intereses reconocidos y protegidos en esta ley»], requieren de la organización y asociación citadas, por la propia lógica de la actuación que comportan los apartados a) y b), y en cuanto al c), configuran una forma de representación legal que, por los motivos dichos en la consideración anterior, no es unecesarion, sino posible, $y$, por consiguiente, sin perjuicio de la posibilidad del ejercicio directo del derecho del consumidor o usuario, por parte de éste.

\section{Aspectos de la representatividad de consumidores y usuarios}

a) Presencia. En especial la función de arbitraje.

En la presentación de la Ley autonómica andaluza ante el Parlamento de Andalucía, el Consejero de Salud y Consumo planteó frente a la "hipertrofia burocrática» una deseable participación de la sociedad civil con capacidad de diálogo para resolver conflictos, dejando como último recurso los procedimientos contenciosos. En otro lugar de su discurso puso de manifiesto la intención del Proyecto de Ley de que los Consejos de Consumo realicen una verdadera función de mediación y arbitraje.

Conecta ese espíritu con una cierta corriente doctrinal que es consciente de que las actuaciones judiciales, excesivamente sobrecargadas, $y$, por tanto, necesariamente lentas, no deben ser el único camino de solución de confictos, sino que debe quedar como último reducto, después de haber sido precedidos de un intento previo de conciliación. No debe olvidarse que no es novedosa esta 
actitud en el ámbito del Derecho positivo, donde la vía administrativa y la reclamación previa a la vía civil y laboral intentaban también cumplir una función de previa reflexión de las partes intervinientes para la evitación del litigio. Pero la potenciación de esta función de arbitraje deriva, sobre todo, de su auténtica institucionalización y de un apoyo jurídico formal de sus decisiones. Las asociaciones de consumidores y usuarios tienen, pues, una doble vertiente de presencia en la sociedad. Por un lado, integrando diversos organismos públicos, $y$, por otro, siendo un interlocutor válido ante los productores y suministradores de bienes y servicios. Por ello, la exposición de motivos de la Ley de Andalucía reitera el propósito expuesto por su presentador ante el Parlamento, a que antes nos referimos: "Se establecen procedimientos para que los representantes de los consumidores y usuarios puedan llegar a soluciones pactadas con los productores y suministradores de bienes $y$ servicios, de forma que los métodos contenciosos y la intervención administrativa queden relegados a recursos últimos.»

\section{b) Intensidad.}

Pero no basta con la simple presencia en el doble aspecto aquí enunciado. Por lo que se refiere a la integración como miembro de derecho en diversos organismos de las Administraciones Públicas, la intervención no puede quedar relegada a un ámbito testimonial y minoritario en el momento de adopción de las decisiones, sino que su voz debe tener suficiente fuerza en la previa configuración del acto, como consecuencia de la plena virtualidad de los derechos enunciados en la Ley estatal y autonómica del Consumo, y del apoyo y fuerza que le presta una representatividad que deriva no sólo de la legitimación de ejercicio -por el buen hacer constante y la fluida intercomunicación- sino también por tener una conciencia firme de la importancia y poder de las bases representadas en el ámbito de la sociedad. Tanto para la presencia en los órganos públicos como en el momento del diálogo frente a los productores y suministradores de bienes y servicios, la convicción de que se ejercita un verdadero derecho público subjetivo reconocido erga omnes, $y$, desde luego, ulteriormente, por los Tribunales, constituye requisito imprescindible para la estimación de la representación ejercida.

\section{c) Organización y viabilidad económico-financiera.}

Pero la plena eficacia de la intensidad en los ámbitos de representación dependen, en gran parte, de la calidad de la función representativa, y no es posible ésta si no se funda en una buena 
formación e información, que no sólo puede derivar del propósito normativo, sino de la autenticidad del servicio prestado. Se requiere para ello de una estructura organizativa dotada de medios personales y materiales que haga posible los propósitos participativos a partir de una constante comunicación con los usuarios y consumidores de la que obtengan fuentes de conocimientos suficientes. Esta "capacitación técnica» constituye elemento imprescindible para la eficacia de las asociaciones y, desde luego, para que tengan el peso social requerido dentro de un Estado democrático. La dotación de medios económico-financieros se constituye también en un pilar ineludible para que esta actuación goce de la necesaria autonomía e independencia.

\section{d) La configuración positiva del derecho de representación.}

Ha de huirse, pues, del peligro de una configuración excesivamente abstracta y genérica de los derechos del consumidor y usuario protegidos por la ley, sustituyéndolo por una serie de disposiciones $y$ actos que los concreten $y$ hagan eficaces. En muchos casos, la formulación legal está hecha, y sólo requiere la instrumentación para su plena efectividad. Así ocurre con el derecho al beneficio de la justicia gratuita prevista en el artículo 20 de la Ley estatal del Consumo para aquellos casos de protección de los derechos de consumidores y usuarios que guarden relación directa con productos o servicios de uso o consumo y referidos en el artículo 2. ${ }^{\circ}, 2$, de dicha Ley; la configuración formal de las asociaciones arbitrales, etc. En suma, que los derechos protegidos tengan una exposición concreta en efectos jurídicos delimitados por el ordenamiento jurídico, y todo ello sin perjuicio de que esos mismos derechos puedan ser ejercitados en otras parcelas del ordenamiento jurídico, puesto que, como dice la exposición de motivos de la Ley estatal del Consumo, «no se excluyen ni suplantan otras actuaciones y desarrollos normativos derivados de ámbitos competenciales cercanos o conocidos, tales como la legislación mercantil, penal o procesal y las normas sobre seguridad industrial, higiene y salud pública, ordenación de la producción y comercio interior». 


\section{AMBITOS DE REPRESENTACION}

Las notas que caracterizan la presencia de los consumidores y usuarios en los distintos organos que, por las competencias que ejercen, exigen una representación de este sector de la participación ciudadana, son las de la dispersión y complejidad (10).

Sin ánimo de ser exhaustivos, vamos a hacer referencia a la presencia indicada en los distintos niveles de las Administraciones Públicas españolas, aunque, muchas veces, esta presencia no deriva directamente de una disposición administrativa, sino de decisiones adoptadas por Empresas u Organismos Públicos o Empresas de Servicios, que así lo comunican directamente a las diferentes organizaciones (11). Por otra parte, la complejidad de éstas y la no agrupación en formas confederadas que permitan ofrecer una sola cara frente a las Administraciones Públicas, impide la presencia que se trata de reivindicar. En la dialéctica posible entre una sola organización estatal y a nivel autonómico, y la multiplicidad de asociaciones locales, esta última forma parece ser la más

(10) Da una idea la siguiente relación de disposiciones concernientes a la representación de las organizaciones de consumidores, usuarios y amas de casa en los órganos de la Administración y Entidades Públicas:

- Ley 33/1980, de 21 de junio, sobre creación del fondo de regulación y organización del mercado de los productos de las pescas y cultivos marinos. Artículo $50^{\circ}, \tilde{n}$ ): Se prevé la presencia de dos representantes de los consumidores en el Consejo General.

- Real Decreto 2852/1980, de 14 de enero, de creación del Fondo de Ordenación y Regulación de Producciones y Precios Agrarios. En el artículo $1 .^{\circ}$, relativo al Consejo General del FORPPA, se prevé un representante de la Asociación de Consumidores, Usuarios y Amas de Casa legalmente reconocidos.

- Real Decreto 2584/1981, de 18 de septiembre, en el que se prevé la participación de las Asociaciones de Consumidores y Usuarios en la Comisión de Vigilancia y Certificación (normalización) del Ministerio de Industria y Energía.

- Real Decreto 816/1982, de 26 de marzo, por el que se prevé representación de las Asociaciones de Consumidores y Usuarios en la Junta Superior de Precios.

- Real Decreto 1456/1982, de 18 de junio, que crea la Comisión Interminiaterial de Ordenación Alimentaria (Organo Colegiado para coordinar y armonizar la regulación de la legislación alimentaria). Artículo 3. ${ }^{\circ}$ : El Presidente puede designar con carácter facultativo a un representante de las Asociaciones de Consumidores y Usuarios, con voz pero sin voto.

- Real Decreto de 22 de abril de 1983, de representación en la Junta Consultiva de Seguros.

- Real Decreto 1900/1984, de 1 de agosto, por el que se prevé la presencia de dos representantes de la Federación de Asociaciones de Amas de Casa y de Consumidores y Usuarios en el Comité de Ordenación del Servicio Público de Energía Eléctrica.

(11) Orden de 1 de marzo de 1985, aprobatoria del Reglamento General de Estructura, Organización y Funcionamiento de los Hospitales de la Seguridad Social, en la que se prevé la presencia de dos representantes de las Asociaciones de Consumidores y Usuarios en la Comisión de Participación Hospitalaria.

Real Decreto $1614 / 1985$, de 1 de agosto, por el que se ordenan las actividades de normalización y certificación, por el que se prevé la presencia de cuatro representantes en el Consejo Superior de Normalización (art. 22.5 de la Ley). 
conveniente, para así obtener los beneficios que en el ámbito municipal o provincial se ofrece a las asociaciones locales, sin perjuicio de un segundo plano de integración en Federaciones autonómicas o estatales, que faciliten la representación en estos ámbitos (12).

Sin más dilaciones, vamos a hacer la anunciada referencia a los distintos ámbitos de representación

\section{En el ámbito estatal}

El Consejo Nacional de Consumo es un organo de representación y consulta de ámbito estatal, donde se prevé la representación de los consumidores y usuarios a que se refiere el artículo 20 de la Ley estatal del Consumo. Dicha previsión, que se recoge en el artículo 22, párrafo $5 .^{\circ}$, de la Ley estatal del Consumo, remite al Gobierno las determinaciones de funciones del Consejo, sin perjuicio de la representación a que acabamos de aludir, que se configura como necesaria por la Ley.

Hasta el momento, no se ha producido el desarrollo reglamentario, imprescindible para la constitución y funcionamiento de este órgano (13).

\section{En el ámbito autonómico (14)}

El Estatuto de Autonomía, en su artículo 18.1.6. ${ }^{\circ}$ atribuye a la Comunidad Autónoma andaluza la competencia exclusiva para la defensa del consumidor, de acuerdo con las bases y la ordenación de la actuación económica general, y la política monetaria del Estado, en los términos de lo dispuesto en los artículos 38, 131 y 141 a), 11 y 13 de la Constitución. La Ley del Consumo de Andalucía prevé, en su artículo 40, la creación del Consejo Andaluz de Consumo, "que estará integrado, en la forma que reglamentariamente se determine, por una representación de las organizaciones empresariales y de las Administraciones Públicas radicadas en el ámbito territorial de la Comunidad Autónoma andaluza». Las funciones de dicho Consejo -según la indicada norma, en su párrafo $2 .^{\circ}-$ son meramente consultivas y de mediación en el arbitraje en

(12) Así, Presencia en la Compañía Telefónica Nacional de España, según carta del Presidente de la Compañía, o acuerdo del Instituto Nacional de Consumidores con la Delegación del Gobierno en la Compañía Telefónica para una presencia de las Asociaciones de la Comunicación y de la Federación de Asociaciones de Consumidores en la Junta Consultiva de la Delegación del Gobierno en la Telefónica.

(13) Si bien tenemos noticias de que existe un proyecto de Decreto de desarrollo de todo el capítulo $6 .^{\circ}$ de la Ley estatal del Consumo.

(14) Como ejemplo de actuaciones en el ámbito autonómico hemos elegido el caso de Andalucía. 
materia de defensa de los consumidores, pero siempre que sea como consecuencia de una elevación desde los Consejos de Consumo de ámbito territorial más restringido o de cuestiones planteadas que excedan del ámbito provincial. Es importante la función de arbitraje prevista, en cuanto que sus decisiones tienen carácter vinculante $y$ ejecutivo para las partes implicadas, sin perjuicio de las competencias de los Juzgados y Tribunales que hayan de intervenir en las cuestiones de índole penal, civil, laboral, etc., que les competa. No obstante, ha de hacerse la salvedad de que el sometimiento a este sistema arbitral tiene carácter voluntario, y, por tanto, la fuerza ejecutiva de sus laudos depende de este previo sometimiento.

Aparte del Consejo dicho, el artículo 17 de la Ley del Consumo de Andalucía prevé la creación de oficinas de información al consumidor para el ámbito de la Comunidad Autónoma andaluza. Su función no es sólo la meramente informativa, sino que constituye puntos de redacción y registro de toda clase de denuncias, reclamaciones, peticiones, etc., y medios de encauzamiento para la mediación de conflictos y para la comunicación entre las Administraciones Públicas y los usuarios.

\section{En el ámbito provincial}

La Ley del Consumo andaluza prevé la creación de un Consejo Provincial de Consumo, que realiza en el indicado ámbito las mismas funciones que el Consejo Andaluz de Consumo.

Tanto el Consejo Provincial como el Consejo Andaluz de Consumo requieren ser desarrollados en su modo de actuación por medio de una normativa reglamentaria de que aún se carece. En el ámbito provincial, también está prevista la existencia de unas oficinas de información al consumidor, en el artículo 19, cuya función es sustitutoria de la carencia de oficinas municipales de información al consumidor, para el servicio correspondiente de aquellos municipios que carezcan de tales oficinas.

\section{En el ámbito municipal}

El artículo 25, g), de la Ley de Bases de Régimen Local determina la competencia municipal en la mediación de la defensa de los consumidores y usuarios, cuestión ésta que precisa aún más el artículo 41 de la Ley estatal del Consumo. En este ámbito, por razón de la proximidad, las oficinas municipales de información al consumidor $y$ al usuario, tienen especial trascendencia, estando especialmente previstas para municipios de más de 20.000 habi- 
tantes y capitales de provincia, mancomunidades o agrupaciones municipales y para aquellos municipios, como los turísticos, de alto grado de población flotante. Esta es la configuración que le da el artículo 18 de la Ley autonómica.

\section{REGIMEN JURIDICO}

Tan dispersa y compleja como la legislación, en cuanto a los ámbitos de representación de consumidores y usuarios, es todo lo concerniente a las referencias que en todo el ordenamiento jurídico se hacen a la defensa de los derechos ciudadanos en esta materia (15).

(15) También sin propósito exhaustivo, recogemos las Leyes y Reglamentos que han de ser tenidos en cuenta en esta materia:

A) Constitución Española: Artículos 22 y 51.

B) Leyes estatales:

- Ley 191/1964, de 24 de diciembre, de Asociaciones («BOE» de 24 de diciembre).

- Ley 26/1984, de 19 de julio, General para la Defensa de Consumidores y Usuarios («BOE» de 24 de julio).

- Ley de Bases de Régimen Local.

Competencia municipal en materia de defensa de usuarios y consumidores. Artículo $25.2, g$ ).

Responsabilidad de las Corporaciones Locales en el control sanitario de alimentos y consumo humano. Artículo $42.3 \mathrm{~d}$ ).

- Ley 14/1986, de 25 de abril («BOE» de 29 de abril), General de Sanidad. Artículo $42.3 d$ ).

C) Reales Decretos:

- Real Decreto 1427/1983, de 25 de mayo («BOE) de 2 de junio), por el que se crea la Comisión Coordinadora de Inspecciones Administrativas sobre bienes y servicios de uso y consumo.

- Real Decreto 1945/1983, de 22 de junio («BOE» de 29 de octubre), por el que se regula el régimen de infracciones y sanciones en materia de uso y consumo.

D) Ordenes ministeriales:

- Orden de 15 de septiembre de 1982, del Ministerio de Sanidad y Consumo, relativa a la asistencia técnica y colaboración de la Administración Central en las Corporaciones Locales en materia de consumo («BOE» de 23 de septiembre), modificada por la de 13 de diciembre de 1982 («BOE» de 15 de diciembre). El INC dará conocimiento de la cooperación y asistencia regulada por esta Orden a las Asociaciones de Consumidores, Usuarios y Amas de Casa, con el fin de alcanzar la máxima coordinación y eficacia en la aplicación de los recursos.

- Orden de 27 de marzo de 1984 («BOE» de 12 de abril) sobre concesión de subvenciones a las Corporaciones Locales en materia de consumo.

- Orden de 25 de febrero de 1987 ( (BBOE» de 13 de marzo) por la que se establecen normas para la concesión y ayuda sobre colaboración y asistencia técnica a las Corporaciones Locales en materia de cosumo.

E) Normas especificas de Andalucía:

- Estatuto de Antonomía de Andalucía.

Competencias exclusivas en materia de defensa de consumidor. Artículo 18.16 (sin perjuicio de la política general de precios y de la legislación de defensa de la competencia).

- Ley 5/1985, de 8 de julio, de Consumidores y Usuarios de Andalucía («BOJA» núm. 71). 
No es el momento de extendernos en un análisis del régimen jurídico de las asociaciones de consumidores y usuarios. A este respecto nos remitimos a lo dicho en la Ley estatal del Consumo, que hace algunas previsiones en cuanto al régimen de sus Estatutos. Dichas previsiones están dirigidas a la exclusión, como decíamos antes, de cualquier forma directa o indirecta del ánimo de lucro y al necesario sistema democrático de la organización y funcionamiento de la asociación.

\section{CONCLUSIONES}

\section{Preámbulo}

Del estudio efectuado a través del presente trabajo y de las deliberaciones realizadas en los correspondientes seminarios $y$ jornadas con las Asociaciones de Amas de Casa, Consumidores y Usuarios, se han obtenido las siguientes conclusiones:

Primera. Se insta a la ultimación del procedimiento de constitución como asociaciones y el acceso a la personificación jurídica de las Asociaciones de Consumidores y Usuarios mediante la oportuna inscripción en los Registros oficiales creados al respecto. Se demanda una coordinación de los Registros públicos creados por la legislación estatal y autonómica en vigor [como son, por ejemplo, el Registro Público de ACU de Andalucía, a que se refiere el apartado a) del artículo 27 de la Ley de Consumidores y Usuarios en Andalucía, de 1985, y el regulado en el párrafo $3 .^{\circ}$ del artículo 20 de la Ley estatal de Consumo de 1984].

Asimismo, se tratará de obtener la declaración de utilidad pública de aquellas asociaciones que no tuvieren dicha declaración, a los efectos de la Ley de Asociaciones y con los beneficios consiguientes.

Segunda. Se demanda la simplificación y coordinación de la regulación de los Organismos en que están representados los consumidores y usuarios, poniendo de manifiesto que la restricción en su presencia cuantitativa debe ser compensada por la valoración de los intereses ciudadanos representados, convencidos del peso específico que tienen en la sociedad.

Tercera. Se demanda la plena efectividad de los beneficios previstos por la legislación para las asociaciones de consumidores y usuarios (como son: el beneficio de justicia gratuita en los casos de protección de los derechos de consumidores y usuarios, cuando guarden relación directa con productos o servicios de uso o consumo común, ordinario y generalizado a que se refiere el artícu- 
lo 20 de la Ley estatal de Consumo; la configuración como órganos de arbitraje de las asociaciones con plena trascendencia jurídica en los pactos con los productores y suministradores de bienes y servicios, etc.), en cuanto que los derechos de los consumidores directa o indirectamente ejercidos (estos últimos dentro de las asociaciones) se configuran como verdaderos derechos públicos subjetivos erga ommes.

Cuarta. Convencidos de la necesidad de estar dotados de una estructura organizativa para la plena eficacia de los objetivos encomendados a las asociaciones, se demanda una regulación de los medios económico-financieros de que deben dotarse $y$, sobre todo, una determinación objetiva de criterios para la percepción de ayudas y subvenciones de actividades y programas que concreten en este aspecto la plena aplicación del principio de igualdad. 